\title{
POSSIBLE ASSOCIATION BETWEEN MATERNAL VIRUS INFECTIONS AND STILLBIRTHS
}

\author{
BY \\ K. AHO, M.D., AND K. CANTELL, M.D. \\ State Serum Institute, Helsinki, \\ L. HJELT, M.D. \\ Children's Clinic, University Central Hospital, Helsinki, \\ AND \\ I. RANTASALO, M.D. \\ Department of Hygiene, University of Helsinki, Finland
}

Some micro-organisms, such as Listeria monocytogenes, Treponema pallidum, and Toxoplasma gondii, frequently give rise to congenital infections which may lead to foetal death in the late months of pregnancy without serious impairment of the mother's health. Maternal rubella is known to be associated with increased perinatal mortality. Foetal death is attributable to an early infection, although the pathological changes which lead to death in the rubella-infected foetus often develop slowly (Siegel, Fuerst, and Peress, 1966). An increasing number of reports, mainly concerned with separate cases, have been made on congenital infections caused by other - viruses (Potter, 1961 ; Brown, 1966). However, there exists no valid information on the overall importance of viral infections in the aetiology of stillbirths.

If the foetus dies in utero, several days usually elapse before the onset of labour, and consequently it is born macerated. This severely hampers attempts to isolate most of the viruses and blurs the histological picture. Since many viral infections lack characteristic clinical features and latent infections may occur, it is very difficult on clinical grounds to evaluate the effect of virus infections on the outcome of pregnancy. A study has accordingly been made of the possible viral aetiology of stillbirths by testing the sera of mothers with stillborn infants for a variety of complement-fixing virus antibodies.

\section{Material ANd Methods}

The present series was compiled from women delivered within the 2-year period 1964-65 in the Women's Clinic of the University Central Hospital, Helsinki. In all, there were 271 stillborn infants from 268 mothers during that period. Foetuses less than $600 \mathrm{~g}$. in weight were not included in the series. Autopsy was performed on all subjects. Biopsies for microscopic examination were always taken from the following organs: lungs (each lobe), thyroid gland, thymus, heart (ventricles and auricles), liver, spleen, adrenal glands, and kidneys.

Blood samples, taken immediately after the delivery, were available from 184 mothers. In four instances, the serum was anticomplementary and thus unsuitable for testing. Tests for complementfixing antibodies were effected by a micro method (Fulton and Dumbell, 1949), employing 2 units of complement.

Influenza $A_{2}, B$ (Lee), C, para-influenza 1 (Sendai), and mumps (Enders) viruses were grown in chick embryos. The allantoic fluids were dialysed against phosphate-buffered saline before use as antigense Adenovirus type 3 was grown in $\mathrm{HeLa}$ cells, reo type 1 , and respiratory syncytial (Randall strain) viruses in a human amnion cell line (U), herpes simplex in primary human amnion cells, and cytomegalovirus ("AD 169") strain in human embryo fibroblasts. The ornithosis antigen used was a commercial product of Behringwerke AG, MarburgLahn, Germany. Mycoplasma pneumoniae was grown on Bacto culture medium enriched with unheated horse serum, yeast extract, glucose, and DNA. The broth culture was concentrated by centrifugation, and the sediment re-suspended in sterile physiological saline.

The serological tests were performed without previous knowledge of the autopsy findings and vice versa.

The $\chi^{2}$-test was employed for the calculation of statistical significance.

\section{RESULTS}

Blood samples suitable for serological tests were available from 180 mothers. The total number of their stillborn infants was 183 (there were three twin-births), and 91 (50 per cent.) of the infants were macerated, indicating that the death had taken place several days before delivery. The series was 
divided into four groups considered appropriate to the present study. Those cases were separated in which the death of the foetus was related to some disease of the mother (Group I), or in which the autopsy revealed malformations (Group II), and the remainder was divided into macerated (Group III) and nonmacerated (Group IV).

Group I.-In 65 instances the death of the foetus was probably related to some obvious disease of the mother, and no other possible reason for the death was found. The group included twelve cases of premature placental separation, 22 of toxaemia of pregnancy, nine of diabetes, and nineteen of erythroblastosis (the frequency is due to selection, since $\mathrm{Rh}$-sensitized mothers from a large area are referred to the Women's Clinic). In addition, there were two bacteriologically-verified cases of listeriosis, and one serologically-verified case of toxoplasmosis. Half of the foetuses in this group were macerated and the average age of the mothers was $28 \cdot 6$ years.

GrouP II.-In 21 instances malformations were present which were in the majority of cases considered to be the primary cause of the death. In four there was a concomitant disease of the mother (premature placental separation in one, erythroblastosis in one, and toxaemia of pregnancy in two), and in three signs of acute asphyxia were observed on autopsy. Five of the foetuses in this group were macerated and the average age of the mothers 28.6 years.

GrouP III.-There were 52 mothers not suffering from any of the diseases commonly associated with stillbirths who had 54 macerated foetuses without detectable malformations; no obvious reason was apparent in these cases for the death of the foetus in utero. The average age of the mothers in this group was $29 \cdot 1$ years.

Group IV.-There were 42 mothers who had 43 stillborn but nonmacerated infants. In five instances, a birth trauma was found at autopsy, and in nineteen there were signs of acute distress. In the majority of the latter death had occurred intra partum. Two infants had pneumonic lesions in the lungs, but in the remaining seventeen no specific lesions were found. Two infants were postmature and eleven immature. The average age of the mothers in this group was $26 \cdot 2$ years.

If any deaths were attributable to maternal virus infections, it is reasonable to assume that such cases belonged mainly to Groups II and III.

During the whole 2-year period tests were made for antibodies against the following viruses: adeno, mumps, para-influenza type 1, herpes simplex, respiratory syncytial, cytomegalo, reo type 1 , and ornithosis. Tests for antibodies against influenza $\mathbf{A}_{2}$, $B$, and $C$ were made during the last two-thirds of the period (during the first third of the period, there were no influenza virus isolations at the State Serum Institute). In addition, tests were made during the whole period for antibodies against Mycoplasma pneumoniae.

The incidence of virus antibodies in the sera of the mothers is shown in the Figure and Table.

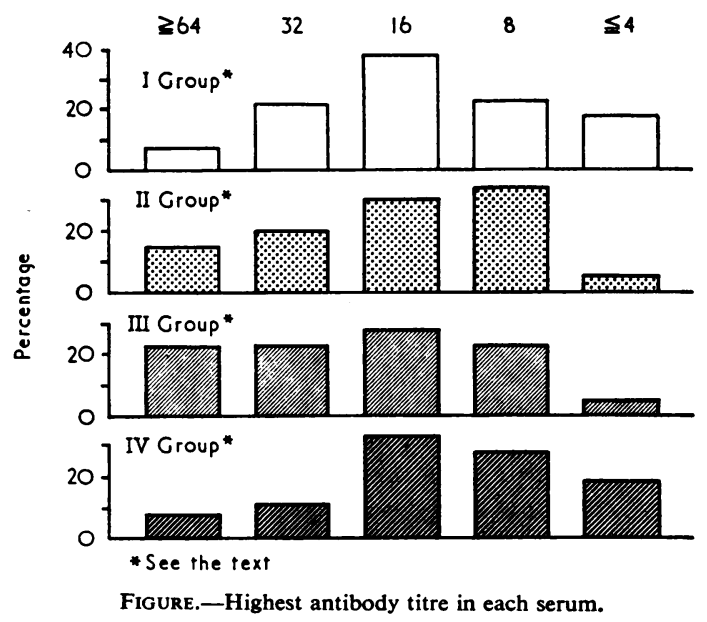

TABLE

HIGH-TITRE ANTIBODIES ( $\geqq 64)$ AGAINST VARIOUS VIRUSES, BY GROUP

\begin{tabular}{|c|c|c|c|c|c|}
\hline \multirow{2}{*}{ Virus } & & \multicolumn{4}{|c|}{ No. of High-Titre Sera in Each Group } \\
\hline & & $I^{*}$ & $\mathrm{II}^{*}$ & III* & IV* \\
\hline $\begin{array}{l}\text { Adeno } \\
\text { Cytomegalo } \\
\text { Herpes simplex } \\
\text { Influenza } \mathbf{A}_{2} \\
\text { Influenza B } \\
\text { Influenza C } \\
\text { Ornithosis. . }\end{array}$ & $\begin{array}{l}\cdots \\
\cdots \\
\cdots \\
\cdots \\
\cdots\end{array}$ & 1 & $\begin{array}{l}1 \\
1\end{array}$ & $\begin{array}{l}6 \\
2 \\
1 \\
2 \\
2 \\
1\end{array}$ & $\begin{array}{l}2 \\
2\end{array}$ \\
\hline Total & $\cdots$ & 4 & 3 & 14 & 4 \\
\hline
\end{tabular}

Note: There were no sera with high-titre antibodies against parainfluenza 1, mumps, reo 1 , and respiratory syncytial viruses, - See text. or Mycoplasma pneumoniae.

The Figure presents the highest antibody titre recorded in each serum without separate treatment of the various virus antibodies. The separate occurrence of high-titre $(\geqq 64)$ antibodies against the various viruses is illustrated in the Table.

The Figure indicates that Group III (mothers with macerated foetuses of unknown cause) included more sera with high antibody titres against some of 
the viruses and less sera with low titres against all the viruses than Groups I and IV. The difference was statistically significant $(0.01>P>0.005)$.

High-titre antibodies were found in twelve out of 52 sera of mothers with macerated foetuses of unknown cause, in two sera against two different viruses. In contrast, high-titre antibodies were found in only ten of the other 128 sera, once against two different viruses. Thus, an excess of eight high-titre sera was present among the macerated foetuses of unknown cause. This corresponds to 15 per cent. of this group, and to 4.5 per cent. of the whole series. The Table suggests that the excess of hightitre sera in the former group was not attributable to antibodies against one virus type; rather, it seems that high-titre antibodies against many different viruses were more frequent in the sera of this group than in the other sera.

No correlation was found between the age of the mother and the incidence of virus antibodies.

\section{COMMENT}

In the present work, the possible role of maternal virus infections in the aetiology of stillbirths was studied by testing the sera of mothers with stillborn infants for a variety of complement-fixing virus antibodies. It was observed that the sera of mothers with macerated foetuses of unknown cause more frequently contained high-titre antibodies against many viruses than did the sera of mothers with stillborn infants in which there was an apparent reason for the death of the foetus. Similarly, the group contained less sera with very low antibody titres against all the viruses tested. The sera of mothers with foetuses showing malformations also more frequently contained high-titre antibodies than did the other sera. However, the series was too small to draw any firm conclusions.

The observed association of virus antibody titres and foetal death was statistically significant. This does not necessarily mean that it is a true association or that it indicates a causal relationship. It was considered possible that other mechanisms might explain the findings. The mother's age may have some correlation with the serum antibody level, and the reasons for foetal death may vary in accordance with the mother's age. Such age correlations were sought but not found. Moreover, susceptibility to viral infections and stillbirths may have some underlying cause in common, although there was no way of testing such a hypothesis.

The occurrence of virus antibodies in high titres indicates no more than that the person concerned has recently suffered from an infection. It is conse- quently impossible to reach any conclusion about the susceptible period in which the infections leading to foetal death might have occurred. It may well be that the great majority of the foetal deaths resulting from maternal virus infections are attributable to an early infection. Either an abortion will occur, or pathological changes leading to death will slowly develop. If the foetus dies in utero, several days usually elapse before the onset of labour. This results in maceration, and in severely macerated foetuses it is difficult to find the malformations responsible for death. Consequently, it is probable that many foetuses dying of malformations were included in the group of macerated foetuses of unknown cause. None the less, at least some virus infections during the late months of pregnancy may be able to kill the foetus.

It can be calculated from the present data that 4.5 per cent. of the stillbirths in this series may have been related to maternal virus infections. The actual figure may be much higher, since there are many other virus infections, not studied in the series, which may influence the outcome of pregnancy. Further, there may have been infections without a high-titre antibody response, or the antibody titre at the moment of delivery may have declined.

\section{SUMMARY}

The sera of 180 mothers with stillborn infants were tested for complement-fixing antibodies against several viruses. The sera of mothers with macerated foetuses of known cause more frequently contained high-titre antibodies against many different viruses than did the other sera. This is consistent with the hypothesis that a proportion of foetal deaths may be attributable to maternal virus infection.

We are grateful to Prof. L. Saxen for valuable comments during the preparation of the manuscript. The cytomegalo and reo antigens were obtained from Prof. P. Halonen, Department of Virology, University of Turku, Finland, and the Mycoplasma pneumoniae antigen from Dr E. Jansson, Aurora Hospital, Helsinki, Finland.

The work was supported by grants from Sigrid Jusélius Foundation, Finland.

\section{REFERENCES}

Brown, G. C. (1966). Advanc. Teratol., 1, 55.

Fulton, F., and Dumbell, K. R. (1949). J. gen. Microbiol. $3,97$.

Potter, E. L. (1961). "Pathology of the Fetus and Infant”, 2nd ed. Year Book Medical Publications, Chicago.

Siegel, M., Fuerst, H. T., and Peress, N. S. (1966). New Engl. J. Med., 274, 768. 